\title{
Screening of physicochemical and functional attributes of fermented beverage (wine) produced from local mango (Mangifera indica) varieties of Uttar Pradesh using novel saccharomyces strain
}

\author{
Vikash Patel $^{1} \cdot$ Abhishek Dutt Tripathi $^{1} \cdot$ Kundan Singh Adhikari $^{2} \cdot$ \\ Anurag Srivastava ${ }^{3}$
}

Revised: 17 July 2020/ Accepted: 13 August 2020/Published online: 1 September 2020

(C) Association of Food Scientists \& Technologists (India) 2020

\begin{abstract}
Mango (Mangifera Indica L.) is a major tropical fruit rich in sugar, organic acids and flavonoids, making it suitable fruit for wine making. In the present study, five varieties of mango (Baganpalli, Langra, Dashehari, Alphonso, and Totapuri) were utilized for wine production using two different yeast strains namely, Saccharomyces cerevisiae MTCC 178 and isolated yeast. The physiochemical analysis of wine produced from chosen mango varieties showed that North Indian local mango variety (Dashehari) gave better results in terms of organoleptic and functional attributes. The Saccharomyces cerevisiae MTCC 178 treated Dashehari wine possessed $6.1 \pm 0.26 \%$ TSS, $2.1 \pm 0.08 \%$ reducing sugar, $0.657 \%$ titratable acidity, $0.11 \pm 0.00 \%$ volatile acidity, $12 \%$ ethanol (v/v) and pH $3.7 \pm 0.10$ comparable to Baganpalli mango wine. HPLC analysis of Saccharomyces cerevisiae MTCC 178 inoculated Dashehari mango wine revealed the presence of primarily; gallic acid (RT-4.4 min), Galloyl-Atype, procyanidin (RT-5.2 min), 2,2,6-Trimethyl-6-vinyltetrahydropyran (RT-8.91 min), $\beta$-Pinene (RT-11.47 min) and Caffeoyl-quinic acid (RT-12.15 min) showing potential antioxidant, anti-cancerous, anti-inflammatory and antimicrobial properties. The local mango varieties wine showed significant $(p<0.05)$ physicochemical properties,
\end{abstract}

Abhishek Dutt Tripathi

abhi_itbhu80@rediffmail.com

1 Department of Dairy Science and Food Technology, Institute of Agricultural Sciences, Banaras Hindu University,

Varanasi, Uttar Pradesh 221005, India

2 Department of Biotechnology, National Taiwan University, Taipei, Taiwan

3 Department of Molecular Biotechnology, University of Turin, Turin, Italy antioxidant potential and ethanol content comparable to Baganpalli wine and was cost effective.

Keywords Mango (Mangifera indica) wine · Mango varieties - Yeast strains - Physicochemical analysis . Functional attributes $\cdot$ Cost-effective

\section{Introduction}

Nowadays, the whole world is facing the Coronavirus disease (COVID-19, caused by the novel coronavirus SARS-CoV-2) threat and declared as a pandemic by WHO on 11 March 2020 (WHO report 2020). There is urgent need to combat the economic crisis in the era of the COVID-19 pandemic, by developing functional foods fortified with bioactive compounds and antioxidants that promote health and immune system of consumers (Galanakis 2020). In nature, fruits are most common source of antioxidants, flavonoids and polyphenols, which plays vital role as immunity booster and prevention of chronic diseases like cancer and AIDS (Kaleem et al. 2015). Tropical fruits like mangoes, pine apple and guava posses huge amount of functional ingredients such as bioactive amines which prevents the cardiovascular disease, neural and gastrointestinal disorders (Gloria et al. 2011). In India, production of mango (Mangifera indica $\mathrm{L}$ ) is very high and it occupies $45.10 \%$ of the total world's production (NHD 2015). Uttar Pradesh is leading mango producing state in India, contributing $23.06 \%$ of total mango production. The total mango production in Uttar Pradesh was found to be 4540.23 thousand MT in 2016-2017 (National Mango Database 2018). In Uttar Pradesh, there are several mango varieties such as Dashehari, Langra, Chausa. Ratole and Bombay, but leading mango varieties are Langra and 
Dashehari. Dashehari is one of the most liked varieties in India owing to its high aromatic flavor. It possess an appropriate mixture of sourness and sweetness, which result in high taste. Mango fruit contains carbohydrate (starch and sugar), organic acid, lipid, pigment, and volatiles, phenolics and antioxidants (Maldonado-Celis et al. 2019). Substantial phenolic compounds found in mangoes are mangiferin, quercetin, gallic acid, benzoic acid, kaempferol, anthocyanins, and protocatechuic acid (Palafox-Carlos et al. 2012). These phenolics plays significant role in preventing cardiovascular diseases, atherosclerosis and decreases the risk of cancer (Pierson et al. 2015).

However, a huge quantity of mango wasted annually because of its short postharvest life. To prevent this huge postharvest loss, mangoes may be processed into diversified products like slices, pulp, jam, squash, nectar, juice, RTS beverages, mango leather etc.

The post-harvest loss of fruits can be minimized by processing them into value added food products such as fermented beverage. Fruit wines are fermentative product, which possess high commercial importance. Wine production begins with the fermentation process followed by aging. Wine is preferred over other alcoholic beverages, as wine is not subjected to distillation process; loss of nutrients is minimum and posses comparable nutritive value as in original fruit (Versari et al. 2015). These are nutritive, tastier and mild stimulants, which substantially utilizes grapes, elderberry or black currant in wine production. Grapes are conventional and generally preferred for wine production owing to its nutritious and desirable aroma and flavor. Although, grapes are preferred raw material for wine production, the availability of grapes is a concern. This allows the opportunity to search for other fruits, especially locally available fruits having low cost and reluctant availability as an alternative (Reddy and Reddy, 2005). It has been previously reported that the ethanol and aromatic components content in mango wine is comparable to those of grape (Reddy et al. 2011). Although, nascent report are available on utilization of south Indian mango variety (Baganpalli) in wine making but not much research work done on local mango variety of Uttar Pradesh. The nutritive value and quality of wine depends upon the inoculum yeast (Coulibely et al. 2016). The non-thermal food processing such as thermo-sonication, ultra high pressure (UHP) and enzyme assisted extraction retain the nutritional and phenolic profile of fruit juice and processed products (Dars et al. 2019). The nutritional and phytochemical composition of mangoes varies with varieties, ripening stages and postharvest storage (Maldonado-Celis et al. 2019). In the present study an attempt was made to study, the physicochemical and functional attributes of fermented beverage (wine) produced from local mango
(Mangifera indica) varieties of Uttar Pradesh using two different yeast cultures.

\section{Materials and methods}

\section{Raw materials and chemicals}

The five varieties of mango (Mangifera indica L) fruits namely; Baganpalli, Langra, Dashehari, Alphonso, and Totapuri were purchased from the local market of Varanasi (Uttar Pradesh, India). All the chemicals and reagents were of analytical grade and were procured form Himedia, Mumbai, India.

\section{Starter culture and maintenance media}

The freeze-dried Saccharomyces cerevisiae MTCC 178 strain was procured from Microbial Type Culture Collection (MTCC), Institute of Microbial Technology, Chandigarh (India). Another yeast isolate (ISY) was obtained from Department of Plant Pathology, Institute of Agricultural Sciences, Banaras Hindu University, Varanasi. The freezedried culture were revived in peptone water, followed by streaking on PDA plates and incubated at $25 \pm 0.2^{\circ} \mathrm{C}$ for $48 \mathrm{~h}$. After $48 \mathrm{~h}$, pure colonies were re-cultured in the sterilized growth medium.

\section{Inoculam preparation}

For inoculam preparation, one inoculation loop of Saccharomyces cerevisiae MTCC 178 and ISY colonies were transferred in $250 \mathrm{~mL}$ conical flask, comprising $100 \mathrm{~mL}$ of mango pulp obtained from different mango varieties individually. The inoculated mango pulp then incubated at $25 \pm 0.2{ }^{\circ} \mathrm{C}$ for seven days. The appearance of bubbles and over ripened fruity odor in pulp showed completion of inoculum preparation.

\section{Preparation of must for fermentation}

Exactly $1 \mathrm{kG}$ each of the mango varieties were weighed. The fruit fermentation process was started by preparing must. The selected mango varieties were then sorted, washed with distilled water and peeled off manually using a knife. After peeling and destoning, fruits were chopped into smaller pieces and then transferred in pulper (Bajaj, India) for pulp extraction. The extracted pulp was then homogenized using laboratory blender. The juice from pulp extracted by squeezing pulp through a muslin cloth. The extracted juice then utilized for fermentation process (Fig. 1). The extracted juice then transferred into $250 \mathrm{~mL}$ clean conical flask and mixed with distilled water $(1: 1$, 


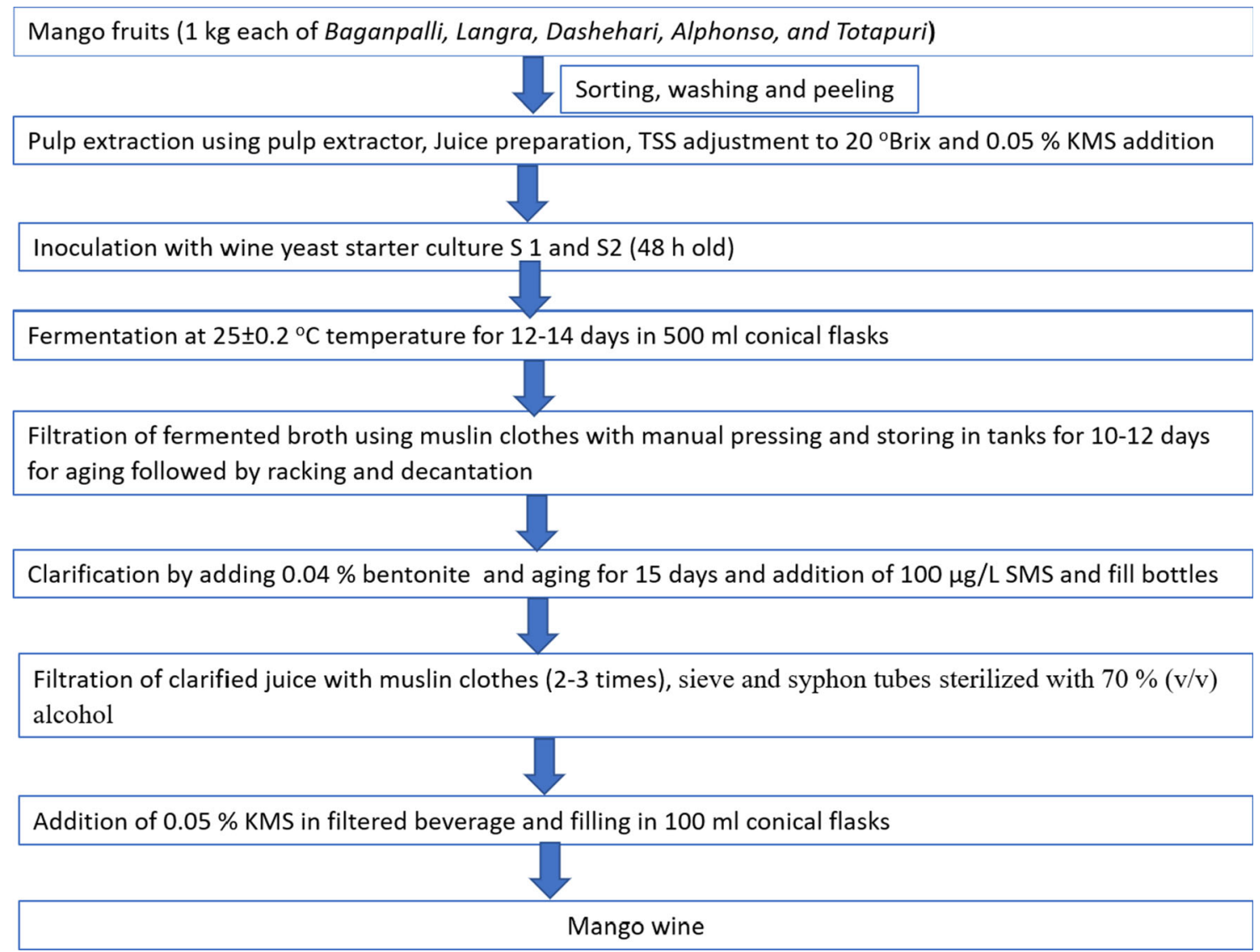

Fig. 1 Production of mango wine using different mango varieties by fermentation using ISY (S1) and Saccharomyces cerevisiae MTCC 178 (S2) strains

w/v). In order to maintain the initial TSS at $20^{\circ}$ Brix, 0.107 , $0.122,0.117,0.116$ and $0.134 \mathrm{kG}$ of sugar added in the must prepared from Alphonso, Langara, Dashehari, Banganapalli and Totapuri varieties, respectively with vigorous stirring. Then, $0.05 \% \quad(\mathrm{w} / \mathrm{v})$ of potassium metabisulphate (KMS) added in the each must samples prior to inoculation of yeast culture. KMS serve as a sterilizer and prevents fermentation before the addition of the yeast starter.

\section{Fermentation}

The batch fermentation was carried out in $500 \mathrm{~mL}$ sterile conical flasks and each flask contained $100 \mathrm{~mL}$ of juice obtained from different mango varieties. $2.5 \mathrm{~mL}$ of $\mathrm{Sac}$ charomyces cerevisiae MTCC 178 (S1) and ISY (S2) inoculum added in the must samples and incubated at $25{ }^{\circ} \mathrm{C}$ for 15 days. After 15 days, the fermented juices filtered through muslin clothes with manual pressing. The extracted juice then clarified by bentonite (a clarifying agent). The clarifying agent prepared by dissolving $500 \mathrm{~g}$ of bentonite in 21 of boiling water and stirred properly to a gel form. This was then allowed to stand for $24 \mathrm{~h}$. Then,
$150 \mathrm{~g}$ of the gel-like bentonite was added into each of the wine samples followed by stirring to get it dissolved properly. After 15 days of clarification, filtration was done using muslin cloth, sieve and syphon tubes sterilized with $70 \%$ (v/v) alcohol. All the wine samples were syphoned into the sieve containing four layers of muslin cloth. The residues removed and the filtrates collected for further physiochemical analysis.

\section{Physicochemical analysis}

The physicochemical properties of juice extracted from different mango varieties and wine developed from them were analyzed. The wine samples produced by using ISY and Saccharomyces cerevisiae MTCC 178 strain were categorized as S1 and S2 samples, respectively. The juice yield, which is an important factor in wine production, was measured as the total quantity of juice obtained from one kilogram of fruit.

TSS was determined by a refractometer (RFM970, BS, India). $\mathrm{pH}$ was determined by $\mathrm{pH}$ meter (Fischer Scientific, USA) and reducing sugar estimation was done by DNS method. Titratable acidity was measured by AOAC (2000) 
method. Volatile acidity (VA) determined by taking $10 \mathrm{~mL}$ of the wine sample and collecting $75 \mathrm{~mL}$ of the distillate in a $250 \mathrm{~mL}$ conical flask. The distillate was titrated against $0.1 \mathrm{~N} \mathrm{NaOH}$ and $1 \%$ phenolphthalein solution used as indicator, until a pink color persisted. The amount of $\mathrm{NaOH}$ used was noted (titer value) and used for calculation as described using AOAC (2000) method as follows:

$$
\begin{aligned}
\mathrm{VA}(\text { in } \mathrm{g} / \mathrm{L} \text { of acetic acid })= & (\text { Sample size / titer value }) \\
\times(0.06) . &
\end{aligned}
$$

\section{Ethanol estimation}

Ethanol content was estimated using Gas chromatography (GC). The fermented broth were centrifuged at $5000 \mathrm{~g}$ for 10 min at $4{ }^{\circ} \mathrm{C}$ in cold centrifuge (Sigma Aldrich, USA). The supernatant collected was mixed with propanoic acid $(1: 1 . \mathrm{v} / \mathrm{v})$ and heated at $100{ }^{\circ} \mathrm{C}$ for enhancing the volatility. For GC analysis, $2 \mu \mathrm{L}$ of samples was injected with the help of micro-syringe (Hamilton, Germany). Nucon gas chromatograph instrument was used with 5\% Carbowax 20 m glass column on Carbopack-B 80/120 mesh. Nitrogen used as a carrier gas with a flow rate of $20 \mathrm{~mL} / \mathrm{min}$. The eluted compounds detected by FID detector. The fuel gas was hydrogen with a flow rate of $40 \mathrm{~mL} / \mathrm{min}$, and the oxidant was air, with a flow rate of $40 \mathrm{~mL} / \mathrm{min}$. The analytes then identified based on their retention time (RT).

\section{Flavonoids determination}

Selection of the variety for determination of flavonoids was made on the basis of ethanol production. The flavonoids were determined by HPLC (Shimdzu, Japan) equipped with 515 HPLC pump and a C-18 column connected to a UV detector. The column was eluted at $40{ }^{\circ} \mathrm{C}$ with a degassed aqueous mobile phase containing $0.1 \%$ sulphuric acid at a flow rate of $0.4 \mathrm{~mL} / \mathrm{min}$. Flavonoids identified based on their retention time. For HPLC analysis, the sample preparation was done by centrifuging the clarified sample in cold centrifuge at $8000 \mathrm{rpm}$ for $15 \mathrm{~min}$ at $4{ }^{\circ} \mathrm{C}$. The supernatant obtained further filtered by membrane filter with mess size of 0.22 microns (Millipore, USA). 2.0 $\mu \mathrm{L}$ of filtered sample was then injected in HPLC column through micro syringe (Hamilton, Germany).

\section{Statistical analysis}

The completely randomized analysis of variance (ANOVA) was used as described by Winner (2004) for data analysis. The mean separation and comparison was done using SPSS version 16.0 software. The significance was accepted at value $(p<0.05)$ and results were expressed as mean \pm standard deviation from the mean.

\section{Results and discussion}

The present study investigated the influence of two yeasts namely; Saccharomyces cerevisiae MTCC 178 and isolated Saccharomyces yeast (ISY) on the quality of wine produced using different mango varieties like Alphonso, Langra, Dashehari, Banganpalli and Totapuri.

\section{Physicochemical properties of mango juice}

The juice yield and physicochemical properties of different varieties of mango juice were analyzed (Table 1). All the mango varieties showed significant $(p<0.05)$ variation in their physicochemical properties. Banganapalli \& Totapuri variety gave the maximum juice yield, whereas, Alphanso and Langra showed the minimum juice yield (Table 1). Juice yield is an important parameter in wine production as it depicts the final quantity of the wine. Fruits with high juice yield were preferred for wine production relative to low juice yielding fruits for economic purposes. The minimum and maximum $\mathrm{pH}$ value of $3.3 \pm 0.35$ to $4.6 \pm 1.30$ were observed in Totapuri and Langra varieties, respectively (Table 1). The $\mathrm{pH}$ of the fruit juice plays an important role in flavor promotion as well as a preservative (Akhtar et al. 2010). The main prerequisite for fermentation is sugar content in the fruit juice. The total soluble solids (TSS) of the mango juice ranged from $13.26 \pm 1.12$ to $18.60 \pm 1.27{ }^{\circ}$ Brix. The minimum and maximum TSS was observed in Totapuri and Alphonso varieties, respectively (Table 1 ). The TSS value of Dashehari and Langra were comparable to Banganapalli varieties. However, the TSS value for local varieties (Dashehari and Langra) was lesser in comparison to previous findings of Rajendra kumar et al. (2001) who reported that Northern India Dashehari variety possessed high TSS of $25.75 \%$ with a total sugar content of $21.2 \%$. The significant $(p<0.05)$ difference in TSS in same cultivar occurred due to demographic variation and harvesting performed in different months. The reducing sugar content of the Dashehari and Langra mango juice was comparable to the Banganapalli (Table 1). Although, maximum and minimum reducing sugar content of $17.40 \pm 1.0$ to $12.50 \pm 1.10 \%$ was observed in Banganapalli and Totapuri varieties, respectively (Table 1). The titratable acidity (TA) as tartaric acid varied from 0.32 to $0.48 \%$. The TA of Langara and Dashehari varieties showed insignificant $(p>0.05)$ variation and was in close proximity to Banganapalli variety (Table 1). 
Table 1 Physicochemical properties of juice of different mango varieties

\begin{tabular}{|c|c|c|c|c|c|}
\hline Mango varieties & Juice yield $(\mathrm{ml} / \mathrm{Kg})$ & $\mathrm{PH}$ & $\operatorname{TSS}\left({ }^{\circ} \mathrm{B}\right)$ & Reducing sugar $(\% \mathrm{w} / \mathrm{v})$ & $\mathrm{TA}^{\#}(\%)$ \\
\hline Alphonso & $550 \pm 15^{\mathrm{aw}^{*}}$ & $3.7 \pm 0.80^{\mathrm{aw*}}$ & $18.60 \pm 1.27^{\mathrm{bx*}}$ & $16.60 \pm 0.80^{\mathrm{aw} *}$ & $0.44 \pm 0.01^{\text {aw** }}$ \\
\hline Langara & $560 \pm 12^{\mathrm{ax}^{* *}}$ & $4.6 \pm 1.30^{\mathrm{aw}^{* *}}$ & $15.57 \pm 0.72^{\mathrm{bw} * *}$ & $14.20 \pm 1.20^{\mathrm{bx} *}$ & $0.32 \pm 0.03^{\mathrm{aw} * *}$ \\
\hline Dashehari & $580 \pm 14^{\mathrm{aw}^{*}}$ & $4.1 \pm 0.95^{\mathrm{bw}}$ & $16.53 \pm 0.92^{\mathrm{bw} * *}$ & $16.20 \pm 1.40^{\mathrm{az} *}$ & $0.39 \pm 0.00^{\mathrm{aw}^{* * *}}$ \\
\hline Banganapalli & $600 \pm 17^{\text {ay* }}$ & $4.2 \pm 0.85^{\mathrm{bw} * *}$ & $16.72 \pm 1.28^{\mathrm{bx*}}$ & $17.40 \pm 1.0^{\mathrm{cw}^{*}}$ & $0.34 \pm 0.06^{\mathrm{aw} *}$ \\
\hline Totapuri & $590 \pm 20^{\mathrm{az}^{*}}$ & $3.3 \pm 0.35^{\mathrm{az} * * *}$ & $13.26 \pm 1.12^{\mathrm{az} * *}$ & $12.50 \pm 1.10^{\mathrm{aw} *}$ & $0.48 \pm 0.04^{\mathrm{aw}^{* *}}$ \\
\hline
\end{tabular}

\#As Tartaric acid; $\dagger$ As acetic acid; First superscript letter (a-d) shows the significant difference $(p<0.05)$ among a particular row, second superscript letter $(\mathrm{w}-\mathrm{z})$ shows the significant difference $(p<0.05)$ among a particular column for a specific attribute. Results are expressed as $\mathrm{n}=3, \mathrm{SD} \pm 0.05, * p \leq 0.05 ; * * p \leq 0.01 ; * * * \leq 0.001$

\section{Physicochemical properties of mango wine}

The $\mathrm{pH}$ level affects the aroma, flavor and mouthfeel of the wine. The $\mathrm{pH}$ value was significantly $(p<0.05)$ affected by inoculam type. S1 samples showed significant $(p<0.05) \mathrm{pH}$ decrease in comparison to $\mathrm{S} 2$ in each mango variety wine (Table 2 ). The maximum $\mathrm{pH}$ values of $4.0 \pm 0.15$ and $4.1 \pm 0.17$ was observed in both the treatments (S1 and S2) of Langra wine. Similarly, minimum $\mathrm{pH}$ value was observed in Totapuri wine in both $\mathrm{S} 1$ and S2 treated samples (Table 2). Dashehari wine showed $\mathrm{pH}$ value of 3.7 in $\mathrm{S} 2$ sample, which was closer to $B a$ ganpalli variety wine. It is previousely reported, that optimum $\mathrm{pH}$ for wine is 3.5-3-8 (Reddy and Reddy, 2005). The $\mathrm{pH}$ value of Alphonso and Totapuri variety wine was lower in comparison to local varieties. The extreme low $\mathrm{pH}$ $(<3.2)$ value imparts acidic taste and is undesirable in wine making. The TSS content varied significantly with different inoculums in all the mango varieties wine. The maximum TSS score of $13.8 \pm 0.78 \& 13.4 \pm 0.47 \%$ was observed in Langra wine with S1 and S2 samples, respectively. The minimum TSS score of $5.2 \pm 0.26 \&$ $6.1 \pm 0.26 \%$ were observed in S2 samples of Banganapalli and Dashehari wine, respectively (Table 2). The significant $(p<0.05)$ reduction in the TSS during wine production may be due to the faster yeast activity that converted sugars into alcohol in lesser time. Previously, a similar finding was reported in peach-based wine (Joshi et al. 2005).

The sugar content of a given fruit is neces-

sary for wine production, as magnitude of sugar fermentation is the measure of alcohol yield. Similarly, reducing sugar content also affects the aroma and flavor of wine, which are the main factors that determine its quality and value (Molina et al. 2007). The reducing sugar content changed significantly $(p<0.05)$ in $\mathrm{S} 2$ samples. The maximum reduction in reducing sugar content was estimated in Banganapalli and Dashehari wine with S1 sample (Table 2). The higher the reduction in reducing sugar content more is ethanol production. The low reducing sugar content $(2.0 \mathrm{~g} / \mathrm{L})$ of Dashehari variety deduced that in S2 sample, conversion of sugar to alcohol was higher in comparison to other mango varieties (Table 2).

The present study also revealed a consistent increase in the TA of all the mango wines throughout the fermentation process. The TA increased significantly after fermentation in both group of samples. Among S1 samples, maximum TA score observed in Alphonso wine, i.e., $0.650 \%$ and Dashehari wine showed a minimum score, i.e., $0.615 \%$ (Table 2). The maximum TA observed in Banganapalli wine, i.e., $0.698 \%$ and Dashehari wine had a minimum score, i.e., 0.657, among S2 samples (Table 2). The TA of fine quality wine is expected to be in the range of 0.5 to $1.0 \%$ (Chilaka et al. 2010). The above finding clearly suggest that $\mathrm{S} 2$ samples showed better acceptability as the yeast culture showed better resistant towards acidic condition and it also facilitates the shelf life of product as higher acidity restricts the bacterial growth and poses tremendous preservative properties. Simultaneously, it can be clearly deduced from the Table 2, that S2 treated Dashehari mango wine showed optimal TA value.

The maximum and minimum volatile acidity (VA) of $0.52 \pm 0.00$ and $0.12 \pm 0.00 \%$ was observed in Totapuri and Langra wine in S1 samples. Similarly, maximum and minimum VA of $0.45 \pm 0.13$ and $0.11 \pm 0.00 \%$ were observed in Totapuri and Dashehari wine, respectively in S2 samples (Table 2). Volatile acidity affects the aroma and flavor of the wine. At higher levels of acetic acid, it causes spoilage of product; also may stimulate the formation of unpleasant volatile compounds viz. ethyl acetate that has an odor like fingernail polish (Moreno and Polo 2005). This clearly suggests that $S 2$ samples of Dashehari wine possessed better organoleptic properties and more shelf life owing to their low VA. 
Table 3 Ethanol content in the wine produced from different mango varieties by fermentation using ISY (S1) and Saccharomyces cerevisiae MTCC 178 (S2) strains

\begin{tabular}{lcr}
\hline Mango variety & \multicolumn{2}{l}{ Ethanol $(\% \mathrm{w} / \mathrm{v})$} \\
\cline { 2 - 3 } & $\mathrm{S}^{\mathrm{a}}$ & $\mathrm{S}^{\mathrm{b}}$ \\
\hline Alphonso & 8.8 & 9.0 \\
Langara & 9.7 & 9.5 \\
Dashehari & 11.5 & 12.0 \\
Banganapalli & 13.0 & 13.0 \\
Totapuri & 8.6 & 8.5 \\
\hline
\end{tabular}

${ }^{\text {a }} \mathrm{S} 1$ represents the ISY

${ }^{\mathrm{b}} \mathrm{S} 2$ represents the Saccharomyces cerevisiae MTCC 178 strain

\section{Ethanol estimation}

The alcohal content of all the samples of mango wine were deduced by GC. Both the yeast culture showed insignificant $(p>0.05)$ variation in alcohol content (Table 3$)$. The Banganapalli and Dashehari wine showed maximum ethanol content of 13 and $12 \%(\mathrm{v} / \mathrm{v})$, respectively in S2 samples. Previously, the alcohol content in Banganapalli was reported to be $14.2 \%$ which is in close proximity to current investigation (Varakumar et al. 2011). However, Totapuri wine showed least ethanol content of $8.5 \%(\mathrm{v} / \mathrm{v})$ (Table 3). There is no previous such reports on Dashehari wine and our investigation suggests that wine prepared from Dashehari mango varieties using S2 strain possesed higher alochol content. Figure 2 A represents the GC profile of pure ethanol, Dashehari and Totapuri mango wine where, the peak obtained at retention time (RT) of 3.90 min represents ethanol. The GC profile of S2 treated Totapuri wine sample showed additional peak (RT$7.98 \mathrm{~min}$ ) which represents isobutyl alcohol (Fig. 3iii).

\section{HPLC analysis}

HPLC analysis of S1 and S2 treated Dashehari and Langra wine was done for estimation of flavonoids and polyphenols. The HPLC profile of different wine showed a variety of flavonoids and polyphenolic compounds represented by their retention time (RT). The S1 treated Dashehari wine comprised gallic acid (4.4 min), Ethyl propionate (4.6 min), 2-furan methanol (4.99 min), methyl gallate (5.21 min), n-Butyl acetate (7.72 min), Protocatechuic acid (9.85 min), Ethyl valerate (10.21 min), p-Hydroxybenzoic acid (11.78 min) (Fig. 3i). Gallic acid (3,4,5-trihydroxybenzoic acid) is phytochemical considered as potential functional food ingredient having high antioxidant properties (Sethiya et al. 2014). Ethyl propionate, 2-furan methanol, methyl gallate, n-Butyl acetate, Ethyl valerate 
Fig. 2 GC-MS chromatogram of the $\mathbf{i}$ standard ethanol, $\mathbf{i i}$ Dashehari and iii Totapuri mango wine. Nucon gas chromatograph instrument was used with 5\% Carbowax $20 \mathrm{~m}$ glass column on Carbopack-B 80/120 mesh. $6 \mathrm{ft}(2 \mathrm{~m}) 2$ mmID1/4 mm, Detectot type: UV
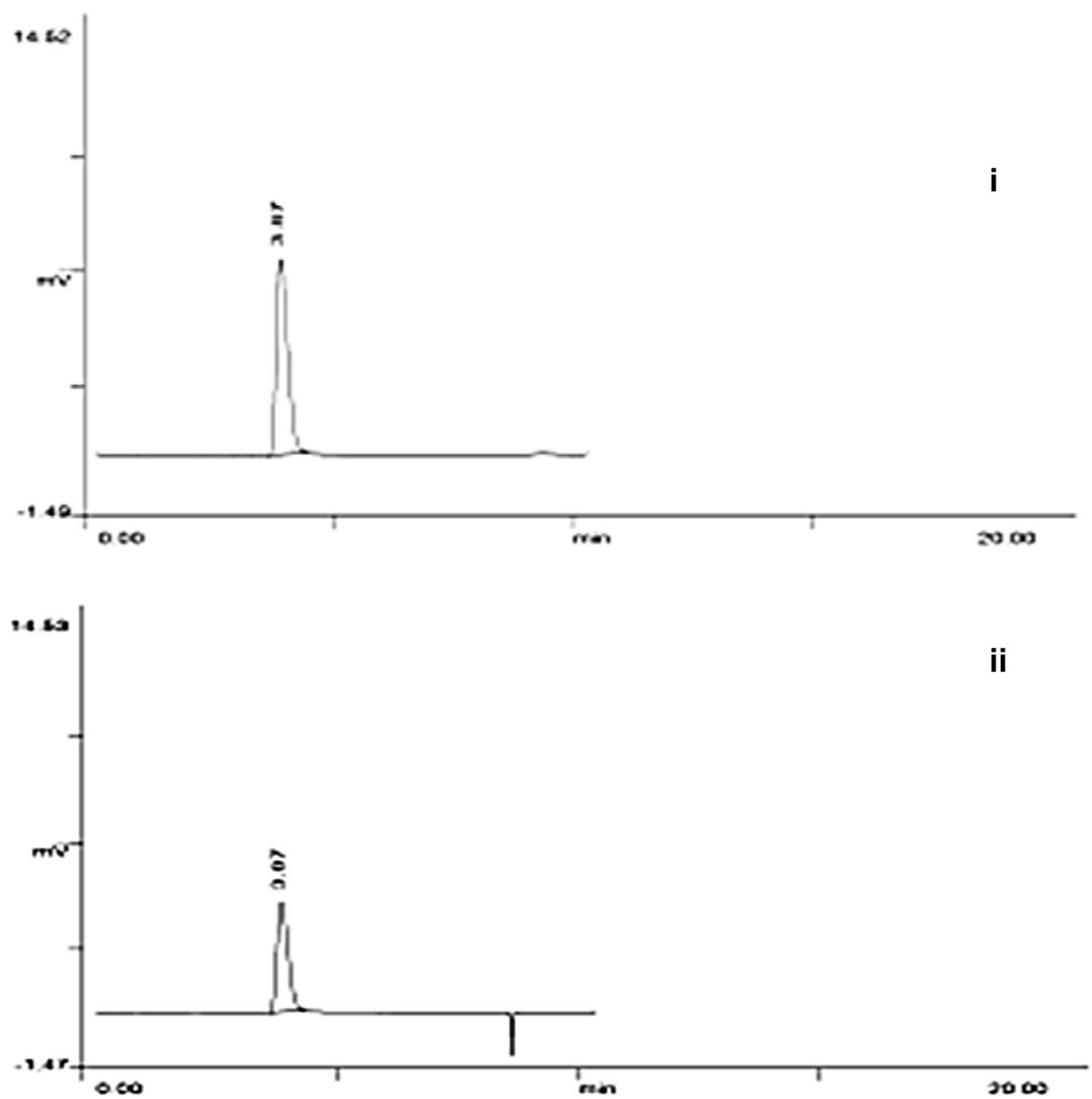

iii

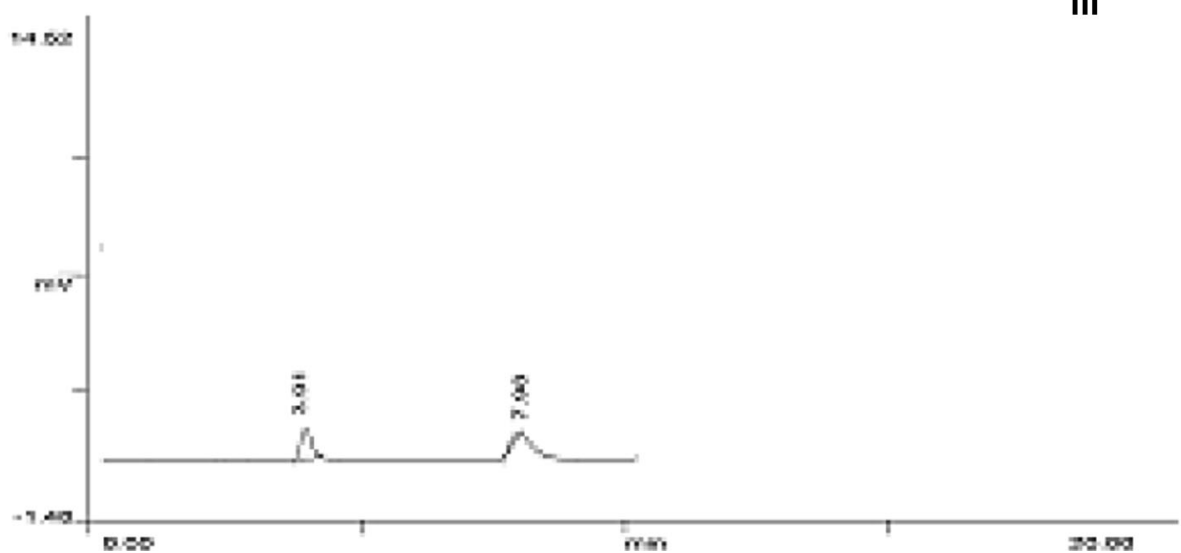

gives characteristic fruity odor, flavor and shows antimicrobial property. Protocatechuic acid (PCA) is phenolic compound which exhibit antioxidant, antimicrobial, anti inflammatory, antidiabetic, anticancer, analgesic, hepatoprotective, neurological and nephro-protective activities (Kakkar and Bais 2014). p-Hydroxybenzoic acid shows antioxidant, antibacterial and antifungal properties. The phenolics present in fermented beverage can be extracted and can serve as additives in food pharma and cosmetic industries as previously reported in the mango seed extracts mixed with palm stearin (Jahurul et al. 2014).

In contrary, S2 treated Dashehari wine comprised; gallic acid (4.4 min), Galloyl-A-type procyanidin (5.2 min), isopropyl alcohol (5.37 $\mathrm{min}$ ), furanone (6.21 $\mathrm{min}$ ), 2,2,6Trimethyl-6-vinyltetrahydropyran (8.91 min), Ethyl valerate (10.21 min), $\beta$-Pinene (11.47 min) and Caffeoyl-quinic acid (12.15 min) (Fig. 3ii). Methyl gallate and Caffeoylquinic acid tannins derivatives have been found to have 
Fig. 3 i HPLC chromatogram of S1 treated Dashehari wine showing individual flavonoid and polyphenol peak at specific retention time (RT). Peak 1 (4.4 min), Peak 2 (4.6 min), Peak 3 (4.99 min), Peak 4 (5.21 min), Peak 7 (7.72 min), Peak 9 (8.47 min), Peak 10 (10.21 min) and peak 12 (11.78 min). ii. HPLC chromatogram of S 2 treated Dashehari wine showing individual flavonoid and polyphenol peak at specific retention time (RT). Peak 1 (4.4 min), Peak 2 (5.2 min), Peak 4 (5.37 min), Peak 5 (6.21 min), Peak 9 (8.91 min), Ethyl valerate $(10.21 \mathrm{~min})$, Peak 12 (11.47 min), Peak 13 (12.15 min). iii. HPLC chromatogram of S 1 treated Langra wine showing individual flavonoid, sugar and polyphenol peak at specific retention time (RT). Peak 1 (4.4 min), Peak 6 (7.19 min), Peak 7 (8.10 min), Peak 8 (8.31 min), Peak 10 (10.12). iv. HPLC chromatogram of S 2 treated Langra wine showing individual flavonoid, sugars and polyphenol peak at specific retention time (RT). Peak 1 (4.4 min), Peak 2 (4.67 min), Peak 3 (4.89 min), Peak 4 (5.32 min), Peak 5 (5.90 min), Peak 7 (8.04 min), Peak 8 (8.35 min), Peak 9 (8.8 min), Peak 10 (10.14 min), Peak 11 (10.44 min) Peak 12 (11.44 min)
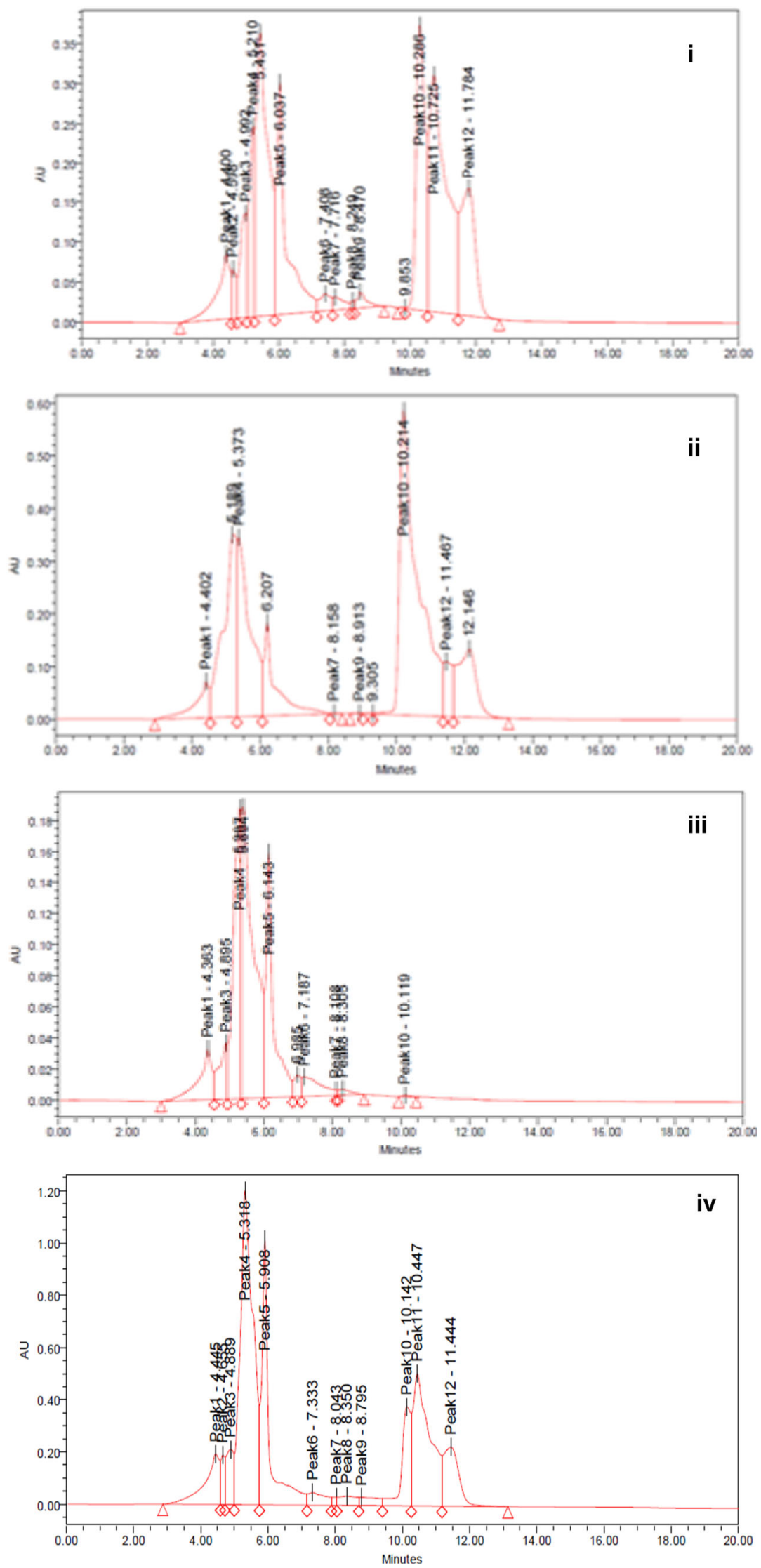
strong antioxidative properties (Okamura et al., 1993). Galloyl-A-type procyanidin is responsible for astringency when consumed (Naish et al., 1993). Caffeoyl-quinic acid is responsible for acidity and prevents microbial growth in wine. 2,2,6-Trimethyl-6-vinyltetrahydropyran also imparts the antioxidant properties by inhibiting the oxidation of hexanal. $\beta$-Pinene is monoterpene present in fruits and performs wide range of pharmacological studies such as antioxidants, antibiotic resistance modulation, anticoagulant, antitumour, antimicrobial, antimalarial, analgesic and anti-inflamatory activities (Salehi et al., 2019).

S1 treated Langra wine comprised; gallic acid (4.4 min), camphene (7.19 min), hexanal (8.10 $\mathrm{min})$, isobutyl alcohol (8.31 min), Ethyl valerate (10.12) (Fig. 3iii). Camphene is terpenoid, which provides cytoprotective, antioxidant potential and prevents lungs inflammation (Tiwari and Kakkar, 2009).

Similarly, S2 treated Langra wine comprised; gallic acid (4.4 $\mathrm{min})$, Ethyl propionate (4.67 $\mathrm{min})$, galloyl glucose (4.89 $\mathrm{min})$, isopropyl alcohol (5.32 $\mathrm{min})$, isobutyl acetate (5.90 $\mathrm{min})$, hexanal $(8.04 \mathrm{~min})$, isobutyl alcohol (8.35 min), 2,2,6-Trimethyl-6-vinyltetrahydropyran (8.8 min), citric acid (10.14 min), maltose (10.44 min) tartaric acid (11.44 min) (Fig. 3iv). The polyphenols and flavonoids attributed higher antioxidant properties in mango wine. Similar antioxidant and functional attributes were reported in pink guava products (Ooi et al. 2019).

\section{Cost economics}

In the present investigation, $580 \mathrm{~mL}$ of juice was extracted from $1 \mathrm{kG}$ of Dashehari mangoes. To produce $1 \mathrm{~L}$ of wine, it requires $1305 \mathrm{~mL}$ of juice as after fermentation and evaporation losses. It clearly deduced that approximately $2.25 \mathrm{kG}$ mangoes are required to produce $1 \mathrm{~L}$ wine, where the cost of raw material (mango) was Rs. 100/- as per the market price. It is also worth mentioning that about $40 \%$ of the raw material cost would be cost of processing including recovery. Hence, $1 \mathrm{~L}$ of mango wine will cost approximately, Rs. 250/-. However, the actual cost of production will be determined only after scale up.

\section{Conclusion}

As mangoes are grown widely as popular fruits, their use in wine production would go a long way in contributing considerably to the economy of not only Indian, but also international mango producers. The quality of wine is predominantly affected by chosen raw material and inoculum type. In the present study, the local mango variety of northern India (Dashehari) inoculated with Saccharomyces cerevisae MTCC178, showed better potential in wine making owing to its new physicochemical and functional attributes and alcohol content. The postharvest loss of local variety during tropical climate is very high; this study targeted the utilization of abundances to minimize wastage. HPLC analysis of Dashehari wine revealed the presence of flavonoids and polyphenols, which can be beneficial in prevention of cancer, skin and cardiovascular diseases. Production can be further scaled up in high capacity reactors for its commercialization as a functional beverage.

Acknowledgements We are grateful to School of Biochemical Engineering, Indian Institute of Technology BHU, Varanasi for providing GC and HPLC facility.

\section{Compliance with ethical standards}

Conflict of interest There is no conflict of interest between the authors. The authors mutually agree to submit the manuscript in the Journal of Food Science and Technology.

\section{References}

Akhtar S, Riaz M, Ahmad A, Nisar A (2010) Physico-chemical, microbiological and sensory stability of chemically preserved mango pulp. Pak J Bot 42:853-862

Chilaka CA, Uchechukwu N, Obidiegwu JE, Akpor OB (2010) Evaluation of the efficiency of yeast isolates from palm wine in diverse fruit wine production. Afr J Food Sci 4(12):764-774

Coulibely WH, N'guessan KF, Coulibaly I, Cot M, Rigou P, Djè KM (2016) Influence of freeze-dried yeast starter cultures on volatile compounds of tchapalo, a traditional sorghum beer from côte d'Ivoire. Beverages 2(35):33-90

Dars AG, Hu K, Liu Q, Abbas A, Xie B, Sun Z (2019) Effect of thermo-sonication and ultra-high pressure on the quality and phenolic profile of mango juice. Foods. https://doi.org/10.3390/ foods 8080298

Galanakis CM (2020) The food systems in the era of the coronavirus (covid-19) pandemic crisis. Foods. https://doi.org/10.3390/ foods 9040523

Gloria MBA, Silva PS, Labanca RA (2011) Functional potential of tropical fruits with respect to free bioactive amines. Food Res Int 44:1264-1268

Jahurul MHA, Zaidul ISM, Norulaini NAN, Sahena F, Kamaruzzaman BY, Ghafoor K, Omar AKM (2014) Cocoa butter replacers from blends of mango seed fat extracted bysupercritical carbon dioxide and palm stearin. Food Res Int 65:401-406

Joshi V, Sharma S, Bhushan S (2005) Effect of method of preparation and cultivar on the quality of strawberry wine. Acta Aliment 34:339-353. https://doi.org/10.1155/2014/952943

Kakkar S, Bais S (2014) A review on protocatechuic acid and its pharmacological potential. ISRN Pharmacol. https://doi.org/10. $1155 / 2014 / 952943$

Kaleem M, Ahmad A, Ahmed Z, Shafiq H (2015) Therapeutic potential of flavonoids and their mechanism of action against microbial and viral infections: a review. Food Res Int 77(2):221-235

Kumar Rajendra, Patel MP, Bose US, Tripathi SK (2001) Physicochemical studies of some important mango varieties of Madhya Pradesh. Crop Res 22:38-42 
Maldonado-Celis ME, Yahia EM, Bedoya R, Landázuri P, Loango N, Aguillón J, Restrepo B, Ospina JCG (2019) Chemical composition of mango (Mangifera indica L) fruit: nutritional and phytochemical compounds. Front Plant Sci 23:9. https://doi.org/ 10.3389/fpls.2019.01073

Molina AM, Swiegers JH, Varela C, Pretorius IS, Agosin E (2007) Influence of wine fermentation temperature on the synthesis of yeast-derived volatile aroma compounds. Appl Microbiol Biotechnol 77:675-687

Moreno AMV, Polo MC (2005) Winemaking biochemistry and microbiology: current knowledge and future trends. Crit Rev Food Sci Nutr 45:265-286

Naish M, Clifford MN, Birch GG (1993) Sensory astringency of 5-Ocaffeoylquinic acid, tannic acid and grape-seed tannin by a timeintensity procedure. J Sci Food and Agricul 61:57-64

Okamura H, Mimura A, Yakou Y, Niwano M, Takahara Y (1993) Antioxidant activity of tannins and flavonoids in Eucalyptus rostrata. Phytochem 33:557-561

Ooi CW, Nagarajan J, Krishnamurthy NP, Nagasunda RR, Raghunandan ME, Galanakis CM (2019) A facile water-induced complexation of lycopene and pectin from pink guava byproduct: Extraction, characterization and kinetic studies. Food Chem 296:47-55

Palafox CH, Yahia E, González AG (2012) Identification and quantification of major phenolic compounds from mango (Mangifera indica cv. Ataulfo) fruit by HPLC-DAD-MS/MSESI and their individual contribution to the antioxidant activity during ripening. Food Chem 135:105-111

Pierson JT, Curry MC, Shaw PN, Dietzgen RG, Gidley MJ, Roberts TSJ, Monteith GR (2015) Polyphenolic contents and the effects of methanol extracts from mango varieties on breast cancer cells. Food Sci Biotechnol 24:265-271

Reddy L, Reddy O (2005) Production and characterization of wine from mango fruit (Mangifera indica L). World $\mathrm{J}$ Microbiol Biotechnol 21:1345-1350
Reddy LV, Reddy LP, Wee YJ, Reddy OVS (2011) Production and characterization of wine with sugarcane piece immobilized yeast biocatalyst. Food Bioprocess Technol 4:142-148

Salehi B, Upadhyay S, Orhan IE, Jugran AK, Jayaweera SLD, Dias DA, Sharopov F, Taheri Y, Martins N, Baghalpour N, Cho WC, Sharifi-Rad J (2019) Therapeutic potential of $\alpha$ - and $\beta$-pinene: a miracle gift of nature. Biomolelues 9(11):738

Sethiya NK, Trivedi A, Mishra S (2014) The total antioxidant content and radical scavenging investigation on 17 phytochemical from dietary plant sources used globally as functional food. Biomed Prev Nutr 4(3):439-444

Tiwari M, Kakkar P (2009) Plant derived antioxidants: geraniol and camphene protect rat alveolar macrophages against t-BHP induced oxidative stress. Toxicol In Vitro 23(2):295-301

Varakumar S, Kumar YS, Reddy OVS (2011) Carotenoid composition of mango (Mangifera indica L.) wine and its antioxidant activity. J Food Bioch 35:1538-1547

Versari A, Ricc KJ, Olejar GP, Parpinello PA, Kilmartin A (2015) Application of Fourier transform infrared (FTIR) spectroscopy in the characterization of tannins. Appl Spect Rev 50(5):407-442

WHO Director-General's Opening Remarks at the Media Briefing on COVID-19-11 March 2020. Available online: https://www. who.int/dg/speeches/detail/who-director-general-s-openingremarks-at-the-mediabriefing-on-covid-19-11-march-2020. Accessed 13 April 2020

Winner L (2004) Introduction to biostatistics. University of Florida, Gainesville, pp 1-20

Publisher's Note Springer Nature remains neutral with regard to jurisdictional claims in published maps and institutional affiliations. 